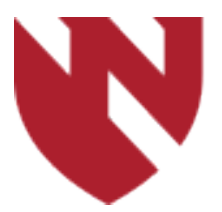

September 2020

\title{
Rural Otolaryngology - A Review of Resident Education and the Impact on Future Practice Selection
}

\author{
Lauren Klute \\ University of Nebraska Medical Center \\ Christie Barnes \\ University of Nebraska Medical Center \\ Matthew Johnson \\ University of Nebraska Medical Center \\ Kari Nelson \\ University of Nebraska Medical Center
}

Tell us how you used this information in this short survey.

Follow this and additional works at: https://digitalcommons.unmc.edu/gmerj

Part of the Higher Education Commons, and the Medicine and Health Sciences Commons

\section{Recommended Citation}

Klute, L., Barnes, C., Johnson, M., , Nelson, K. Rural Otolaryngology - A Review of Resident Education and the Impact on Future Practice Selection. Graduate Medical Education Research Journal. 2020 Sep 29; 2(1). https://digitalcommons.unmc.edu/gmerj/vol2/iss1/63 


\section{Rural Otolaryngology - A Review of Resident Education and the Impact on Future Practice Selection}

\section{Creative Commons License}

\section{(c) (1) $\Theta(9$}

This work is licensed under a Creative Commons Attribution-Noncommercial-No Derivative Works 4.0 License. 
state. Several medications, including hormonal therapies, constipation inducing drugs, laxatives, and illicit drugs have been associated with ischemic colitis. Taking a thorough medication history is essential when a patient is diagnosed with ischemic colitis. The recognition of medication induced colonic ischemia and prompt

discontinuation of offending agent is vital to patient outcomes.

https://doi.org/10.32873/unmc.dc.gmerj.2.1.060

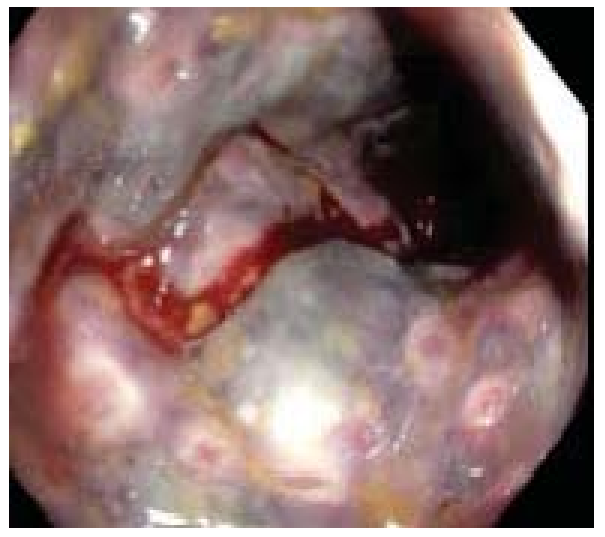

Figure 1. Colonoscopy demonstrating a diffusely edematous, ulcerated, and violaceous segment of the sigmoid colon

\section{Rural Otolaryngology - A Review of Resident Education and the Impact on Future Practice Selection Lauren Klute', Christie Barnes', Matthew Johnson 1,2, Kari Nelson ${ }^{3}$ \\ ${ }^{1}$ University of Nebraska Medical Center, Department of Otolaryngology \\ ${ }^{2}$ Ear, Nose and Throat Physicians of Kearney, Kearney, NE \\ ${ }^{3}$ University of Nebraska Medical Center, Department of Graduate Medical Education}

\section{Mentor: Christie Barnes}

Program: Otolaryngology

Type: Original Research

Background: The University of Nebraska Medical Center, Department of Otolaryngology - Head and Neck Surgery (OHNS) established a rural residency rotation in Kearney, Nebraska, in 2016. Each resident spends two months on the service as a junior (years two or three), and two months as a senior (years four or five). It has been cited that residency rotations in rural practices are a significant factor in retention of family practice and surgical physicians, however, there is not similar data available for Otolaryngology. This study provides data from current and prior OHNS residents on their rural rotation experience and the factors that contributed to future practice decisions.

Methods: In this qualitative study, we used a semi-structured interview guide to probe rural rotation participants on their experience and the influence the rotation had on their future practice decisions.

Results: The rural rotation was influential in residents' selection of future practice and did encourage residents to pursue rural practice. The benefits of the rotation included increased autonomy, diversity of cases, education in the private practice environment, and improved quality of life. The disadvantages included time away from family.

Conclusion: The University of Nebraska Medical Center OHNS Rural Rotation provides invaluable experience, education, and training. The rotation was influential in the selection of future practices and encouraged several residents to pursue rural Otolaryngology practices. A rural rotation experience in residency may lead to retention of Otolaryngologists for rural areas.

https://doi.org/10.32873/unmc.dc.gmerj.2.1.062

\section{Problem and Creating Guidelines Matthew A. Mormino' \\ ${ }^{1}$ University of Nebraska Medical Center, Department of Orthopaedic Surgery and Rehabilitation \\ 2University of Nebraska Medical Center, College of Medicine \\ ${ }^{3}$ Loma Linda University Medical Center \\ ${ }^{4}$ University of Nebraska Medical Center, College of Public Health, Department of Biostatistics}

Patterns of Opiate Use and Prescription Practices in Isolated Orthopedic Trauma Part One: Defining the

David J. Kusin'1, Emily A. Boes², Zachary C. Bailey ${ }^{1}$, Erin L. Stockwell', Ryan E. Miller ${ }^{3}$, Kaeli K. Samson ${ }^{4}$, Sara M. Putnam¹, Justin C. Siebler ${ }^{1}$,

Mentor: Matthew A Mormino

Program: Orthopaedic Surgery and Rehabilitation

Type: Original Research

Background: About $80 \%$ of the global supply of opiates is consumed in the United States, yet opioid use is associated with significant morbidity and safer approaches to pain control exist1-15. The purpose of this two- part study is to quantify our opioid prescribing practices and to formulate guidelines for safe and effective opioid stewardship.

Methods: The quantity of opioids prescribed (as Morphine Milligram Equivalents) at discharge and in the 90 days after surgery in adults with operatively treated, isolated fractures was correlated to patient demographics, comorbidities, fracture characteristics, and patient reported pain control.
Results: There were 56 males (47\%) and 63 females $(53 \%)$. Ankle fractures were the most common injury (34.2\%). 9 (7.6\%) fractures were open. The mean VAS pain scores at the first and second postoperative visits were 4.1 and 3.4, respectively. The mean initial quantity of opiates prescribed for all patients was $390 \mathrm{MME}$ and the mean total quantity was 535 MME (range 60-1800, Stdev 256; 60-2550, Stdev 245, respectively). 44\% of patients were prescribed refills. Greater 